\title{
AN APPARATUS FOR MAGNETIC TESTING AT HIGH MAGNETIZING FORCES
}

\author{
By Raymond L. Sanford and Evert G. Bennett
}

\section{ABSTRACT}

Description of an apparatus suitable for general magnetic testing in the range of values of magnetizing force from 100 to 1,000 oersters. Specimens of rectangular cross-section from one-half inch $(1.27 \mathrm{~cm})$ to $1 \frac{1}{2}$ inches $(3.8 \mathrm{em})$ in width and any thickness up to three-fourths inch $(1.9 \mathrm{~cm})$ can he tested with an accuracy estimated to be within 2 per cent. The apparatus is convenient and simple to operate, and does not heat the specimen.

\section{CONTENTS}

Page

567

I. Introduction

II. Experimental investigation of the magnetic circuit

III. Description of apparatus

570

571

\section{INTRODUCTION}

As a result of recent developments in magnetic materials, it has become necessary to increase the maximum value of magnetizing force used in magnetic testing. Whereas, previously, a maximum value of 300 oersteds was ample, forces up to 1,000 oersteds are now required. In the design of apparatus to work at these higher values of magnetizing force, two points in particular must be kept in mind if satisfactory results are to be obtained. First, the magnetic circuit must be of such a form that uniform magnetization is produced in the part of the specimen under test. Failure to meet this condition results in errors in the observed values of both magnetizing force and induction. Second, the apparatus should be so designed that heating of the specimen is avoided. The current required for the application of high magnetizing forces produces a considerable amount of heat which should not be allowed to raise the temperature of the specimen by as much as $5^{\circ} \mathrm{C}$., since it is well known that even small changes in temperature alter the magnetic properties to an extent that can not be neglected.

The most obvious way to obtain uniform magnetization is by surrounding the specimen with the magnetizing coil. If this is done, however, some means of keeping the specimen cool, such as a water jacket, must be provided. This is not convenient and it seems better to adopt an arrangement based on the well-known isthmus method, with a magnetic circuit such as to give uniform magnetization.

An apparatus previously described ${ }^{1}$ meets the requirements, but is not convenient for routine testing because a separate set of pole pieces and test coils is required for each different size of specimen. The present investigation was undertaken to see if it might not be possible to design a single set of pole pieces and test coils for this

1 Sanford, A Method for the Standardization of Permeameters at High Magnetizing Forces, B. S. Jour. Research, vol. 6 (R P279), p. $355,1931$. 
apparatus which would give satisfactory results for a considerable range of sizes of specimens. The final result was an apparatus capable of testing specimens of rectangular section from one-half inch $(1.27 \mathrm{~cm})$ to $1 \frac{1}{2}$ inches $(3.8 \mathrm{~cm})$ in width and any thickness up to three-fourths inch $(1.9 \mathrm{~cm})$. The accuracy is sufficient to meet ordinary commercial requirements in the range of magnetizing force values from 100 to 1,000 oersteds.

\section{EXPERIMENTAL INVESTIGATION OF THE MAGNETIC CIRCUIT}

The magnetic circuit is shown in Figure 1. The test specimen is clamped in pole pieces between two similar $U$-shaped yokes of laminated silicon steel upon which are wound the magnetizing coils. In the previous apparatus pole pieces $1 \mathrm{~cm}$ thick surrounded the test specimen at each end. In the present arrangement these pole pieces are replaced by simple laminated blocks of rectangular section $5 \mathrm{~cm}$ wide, $3 \mathrm{~cm}$ thick, and $12 \mathrm{~cm}$ long as shown in the figure. This change

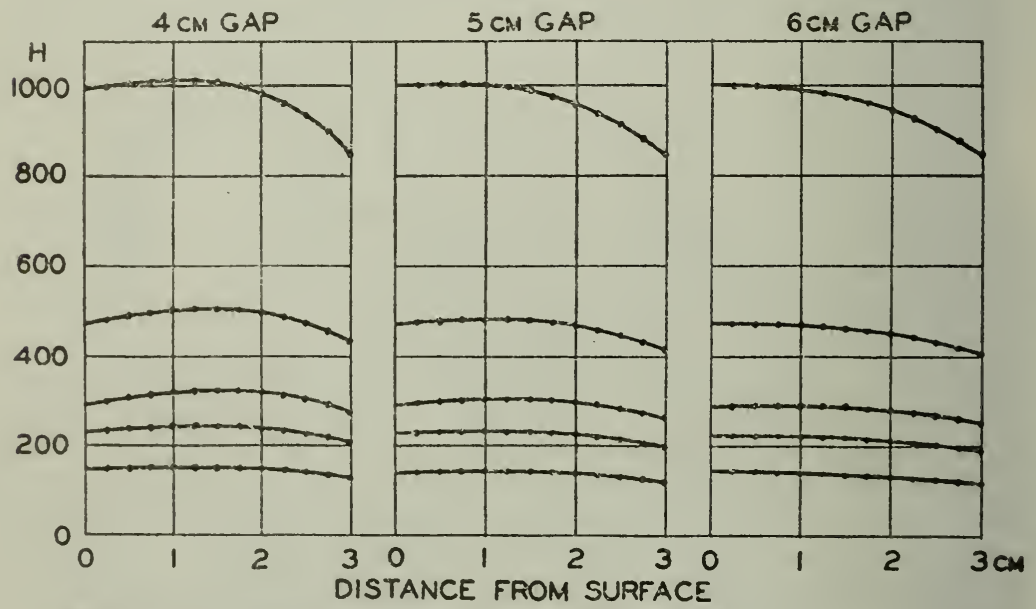

FIGURE 2.-Radial distribution of the field for different lengths of gap

was made so as to obviate the necessity of providing a separate set of pole pieces for each size of specimen to be tested.

In order to determine whether or not this circuit would prove to be satisfactory, and, if so, to fix upon the best gap length and test coil dimensions, the field between the ends of the pole pieces was explored by means of a small test coil. ${ }^{2}$ Various gap lengths and thicknesses of specimen were used. The distribution of induction along the length of the specimen between the pole pieces was also determined for each condition.

Typical results of this exploration are shown in Figures 2 to 5 . Figure 2 shows the radial distribution of the field with a specimen one-half inch thick. The $4 \mathrm{~cm}$ gap is evidently too short to obtain uniformity. However, for gaps of from 5 to $6 \mathrm{~cm}$, the field is substantially uniform for a distance of at least $1 \mathrm{~cm}$ from the surface of the specimen. Figure 3 shows the longitudinal distribution of the

'A preliminary check on the uniformity of the fleld was made by means of an "iron-filing diagram" using "Magnaflux" irou powder. The diagram obtained is shown in Fig. 1. 


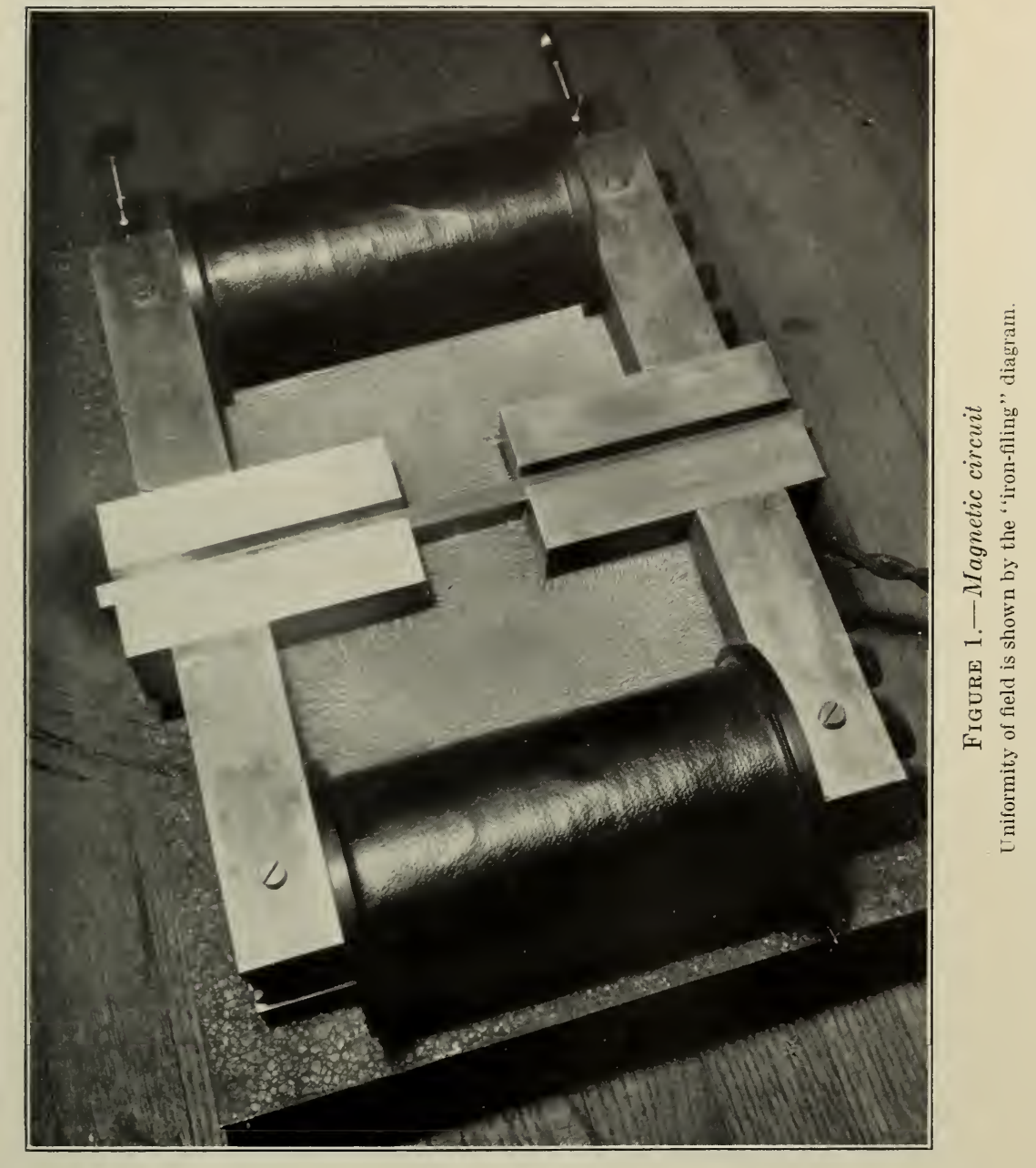


field. As the exploring coil had a length of $1 \mathrm{~cm}$, the points represent average values over a centimeter of length. However, the results

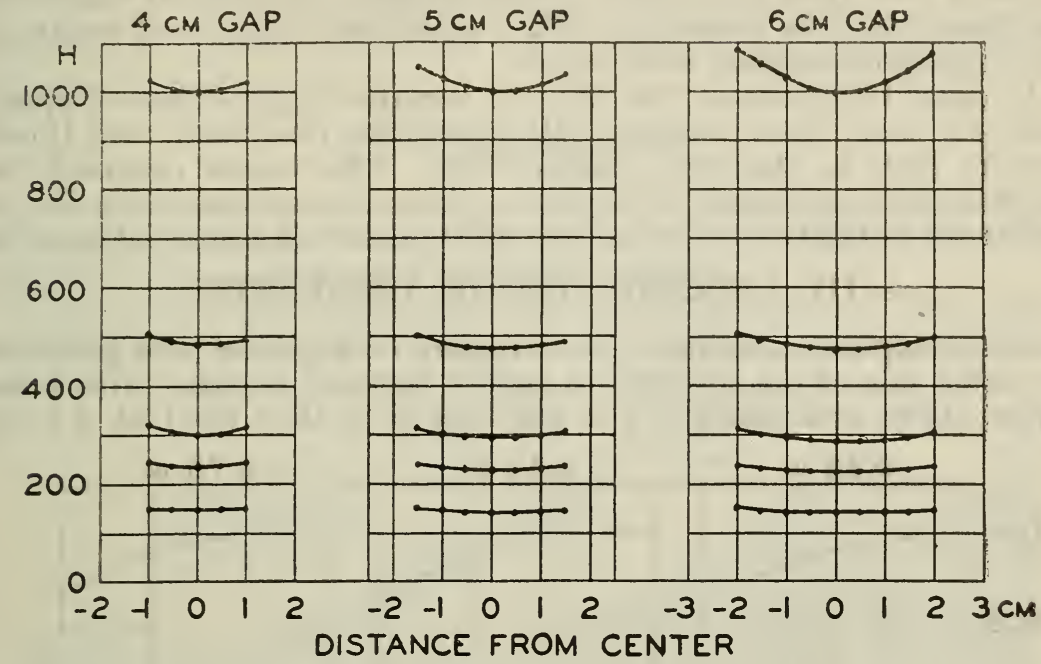

FIGURE 3.-Longitudinal distribution of the field for different lengths of gap

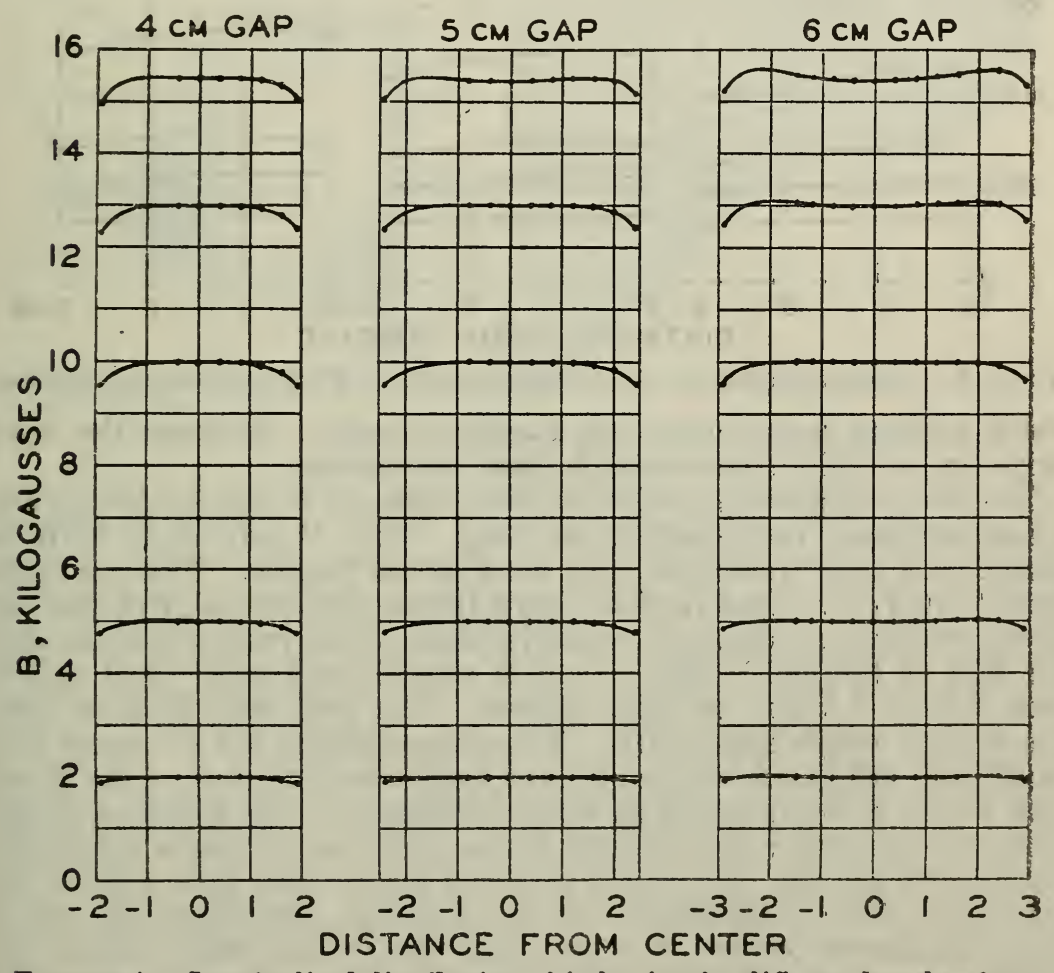

Frgore 4.-Longitudinal distribution of induction for different lengths of gap indicate that there is no appreciable variation over the middle centimeter so that it should be safe to use a test coil $1 \mathrm{~cm}$ long. Figure 4 
shows the longitudinal distribution of $B$ for the different gaps. From these results it was concluded that with a test coil $1 \mathrm{~cm}$ long extending not over $1 \mathrm{~cm}$ from the surface of the specimen, the value of magnetizing force could be measured with a satisfactory degree of accuracy for a specimen one-half inch thick.

In order to determine the effect of variation in thickness of specimen, the tests were repeated with specimens one-fourth and threefourths inch in thickness, respectively. The values obtained for the $5 \mathrm{~cm}$ gap are shown in Figure 5 . There is some variation due to difference in thickness but not enough to cause an appreciable error.

\section{DESCRIPTION OF APPARATUS}

In the apparatus as finally constructed, each pair of pole pieces on the same side of the specimen is rigidly fastened together with brass strips above and below. The gap length is thus fixed at $5.5 \mathrm{~cm}$

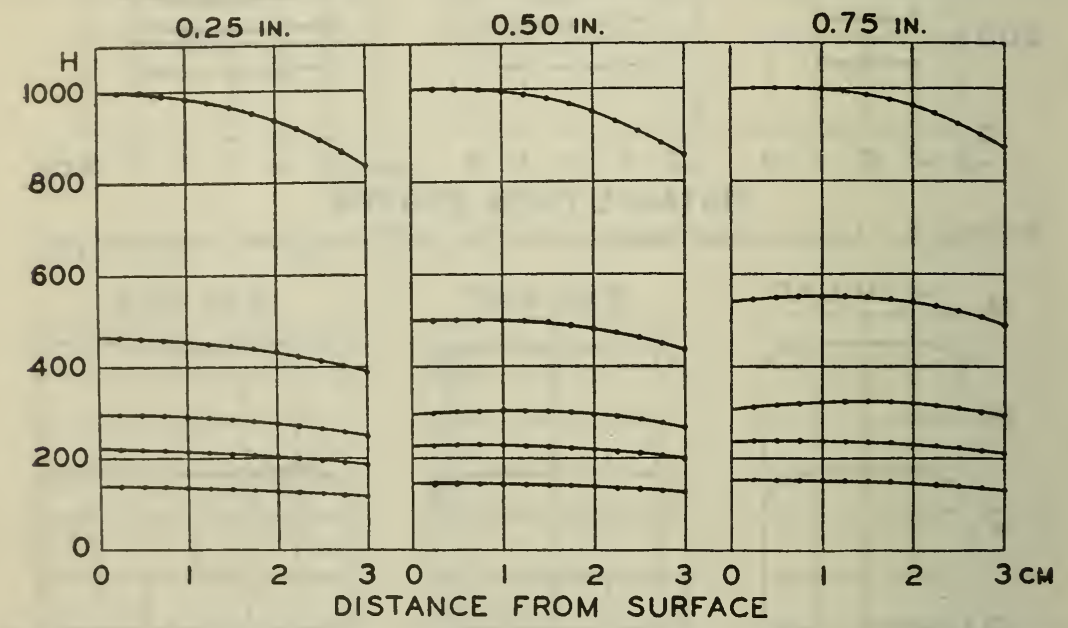

FIGURE 5.-Radial distribution of the field for specimens of different values of thickness

which appears to give the best average results. Between the brass strips on one side is mounted the test coil system.

The test coil system consists of three coils-a $B$ coil, an $H$ coil, and a compensating coil-each $1 \mathrm{~cm}$ long. The $B$ coil of 25 turns is wound on a split brass form with hard rubber flanges. The coil opening is 2 by $4 \mathrm{~cm}$. One vertical side is in line with the edge of the pole pieces so that a specimen clamped in place comes just in contact with the side of the coil. The $H$ coil is wound on a solid hard rubber form 2.5 by $7.5 \mathrm{~mm}$ in cross section. The coil has 725 area turns which gives ample sensitivity. The compensating coil is wound over the $H$ coil and has a number of area turns equal to that of the $B$ coil with which it is connected in series, opposing. The function of this compensating coil is to eliminate the large air correction which would result from the use of a $B$ coil of much larger area than that of the specimen. The combination of $H$ coil and compensating coil is placed adjacent to the $B$ coil so that the $H$ coil comes within the uniform part of the field. The whole combination extends only slightly more than $1 \mathrm{~cm}$ from the surface of the specimen. The arrangement of the pole pieces and test-coil system is indicated in the diagram of Figure 6. 
The pole pieces are not fastened to the yokes and can be removed so that the yokes can be used for other purposes.

The rest of the apparatus consists of a heavily over-damped ballistic galvanometer with the usual calibrating inductor, reversing switches, rheostats, etc.

\section{PERFORMANCE}

After the apparatus was assembled in its final form, several tests were made to check its accuracy and to determine the influence of various factors encountered in general testing.

Check tests with the previous form of pole pieces and concentric test coils gave agreement within the experimental error and demon-

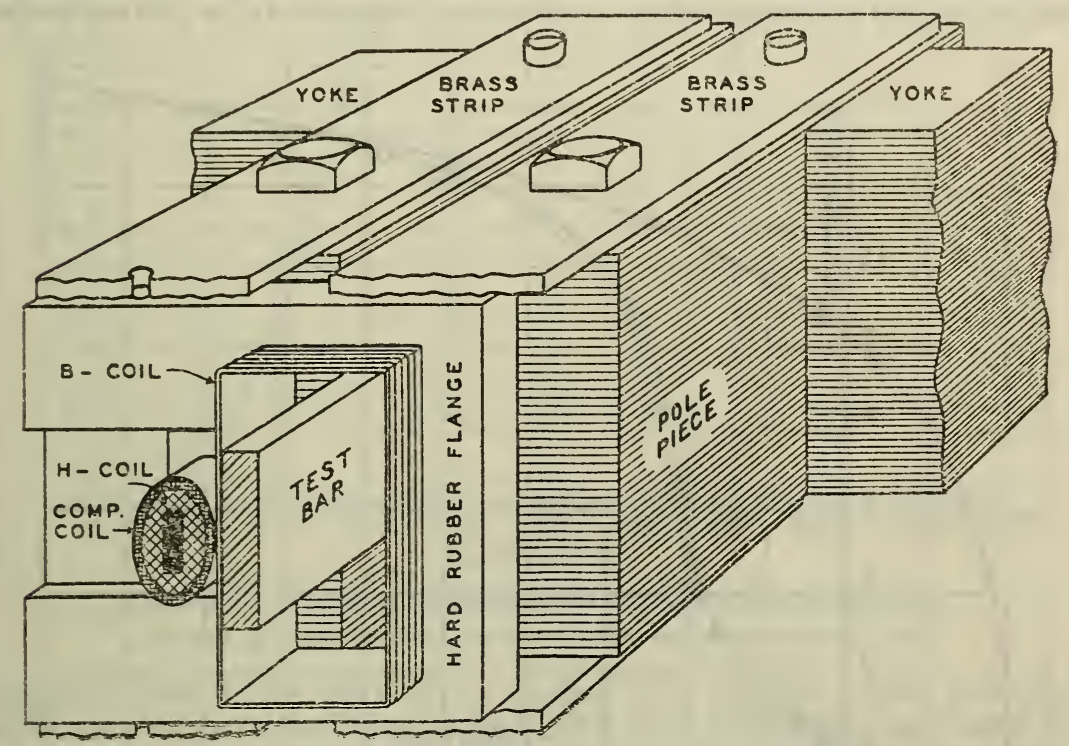

FigURe 6.-Arrangement of pole pieces and test coil system

strated that the degree of reproducibility was satisfactory. It seemed desirable, however, to obtain a comparison with some entirely independent method of known accuracy. Fortunately, there was available a bar of hardened cobalt magnet steel $112 \mathrm{~cm}$ long. This bar which was furnished through the courtesy of L. E. Howard, director of research of the Simonds Saw \& Steel Co., had been used in previous investigations and was known to have a satisfactory degree of uniformity along its length. The cross-section was approximately 1 by $2.5 \mathrm{~cm}$. A 25 -turn $B$ coil was wound directly on the bar at the middle. A thin $H$ coil was placed against this and a test made in a straight solenoid $90 \mathrm{~cm}$ long. The values thus obtained were taken as correct. The bar was then tested in the new apparatus and the results were compared. Figure 7 shows the agreement obtained. The full lines represent the results obtained with the solenoid and the circles indicate points obtained with the new apparatus. While the agreement is not perfect the differences do not exceed 1 per cent. It would have been desirable to repeat the tests with other bars of different cross sections but, unfortunately, satisfactory specimens were not available. 
In order to determine the effect of the length of the specimen, a test was made on a bar $25 \mathrm{~cm}$ long. Equal lengths were then cut off from each end making the specimen only $7.5 \mathrm{~cm}$ long. This gave only $1 \mathrm{~cm}$ length of contact at each end. Some difference was noted in the steep part of the curve, but there was exact agreement in the upper part of the curve. The short length gave about 1 per cent higher value of residual induction and the same value of coercive force as found for the full length.

The lower limit of magnetizing force was determined by testing several uniform standard bars calibrated by means of the Burrows permeameter. For the low part of the curve the apparatus gives values of $H$ which are too high. In all cases, however, the curves coincided for magnetizing forces of 100 oersteds or over so the lower limit at which accurate values are obtained appears to be 100 oersteds.

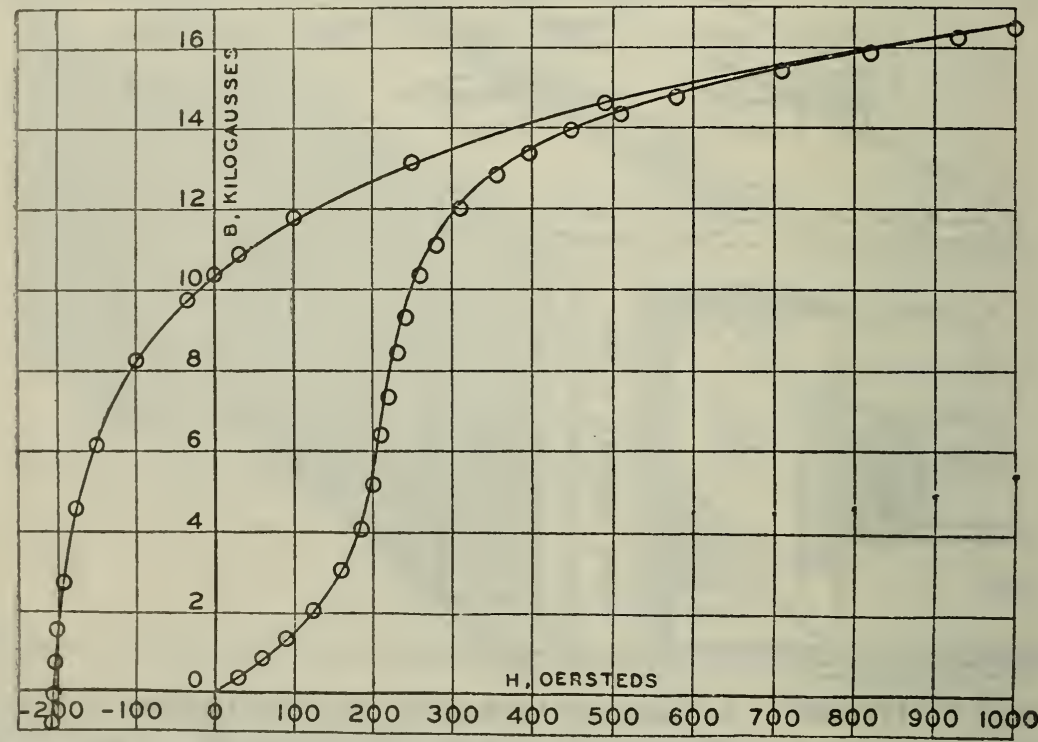

FIGURE 7.-Comparison of results obtained by a long solenoid and by the new apparatus

Full lines represent solenoid values; circles are points by the new apparatus

One possible source of error, especially for specimens of small cross section, is lack of uniformity of field throughout the area inclosed by the $B$ coil. This would lead to incorrect compensation with a consequent error in the observed value of the induction. In order to determine the magnitude of this effect under the most unfavorable conditions, a test coil was wound directly on a specimen one-fourth inch thick and the results obtained with this coil were compared with those obtained with the compensated system. The compensated system gave values of induction slightly lower than those obtained with the coil wound on the specimen, but the difference was nowhere as great as 1 per cent. In Figure 8 the full line represents the curve obtrined with the coil on the specimen and the circles represent points obtained with the compensated $B$ coil. 
In the light of these results, it appears that the apparatus is suitable for general magnetic testing within the range of magnetizing force values from 100 to 1,000 oersteds. The symmetrical magnetic circuit and absence of heating are distinct advantages. The apparatus is convenient and simple to operate and gives results on specimens from

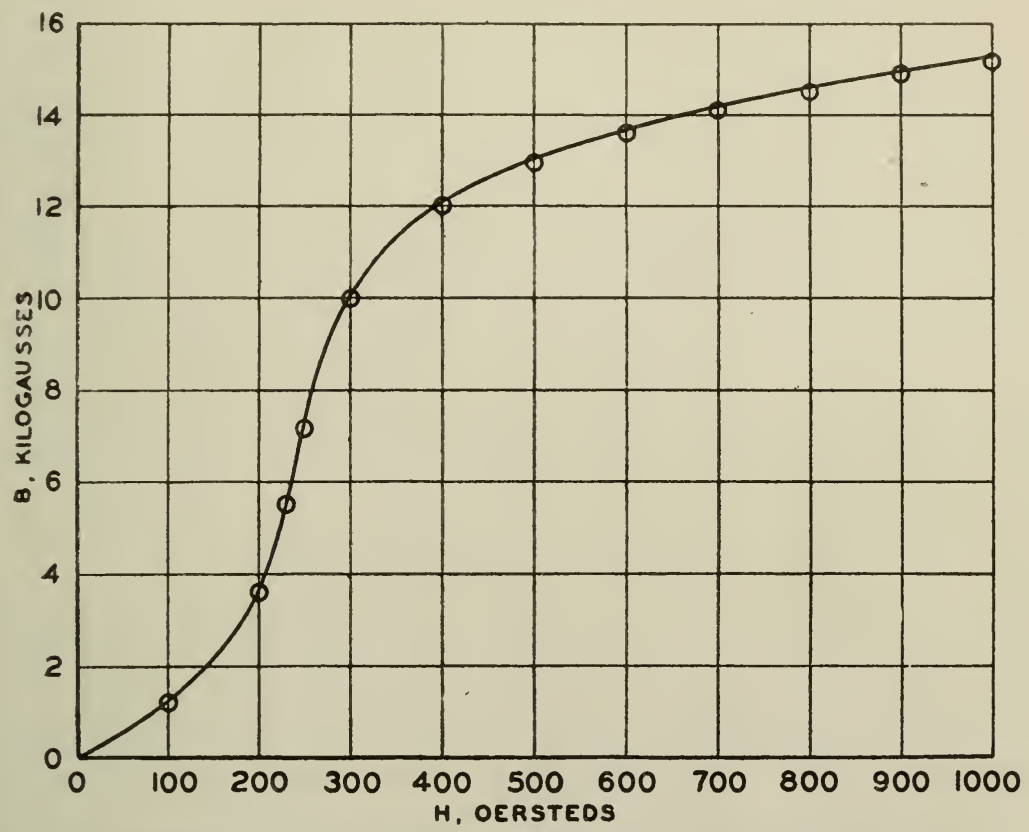

FIGURE 8.-Showing differences due to imperfect compensation

Full lines represent true values; circles are points by the compensated $B$ coll

one-half inch $(1.27 \mathrm{~cm})$ to $1 \frac{1}{2}$ inches $(3.8 \mathrm{~cm})$ in width and any thickness up to three-fourths inch $(1.9 \mathrm{~cm})$ which are estimated to be accurate within 2 per cent. It has been adopted for routine testing in the magnetic measurements section of the Bureau of Standards.

Washington, January 31, 1933. 